UCRL-ID-120900

\title{
Simulation of Phase Structures
}

RECEIVED

OCT 061995

Janice Lawson

\section{OSTI}

April 20, 1995

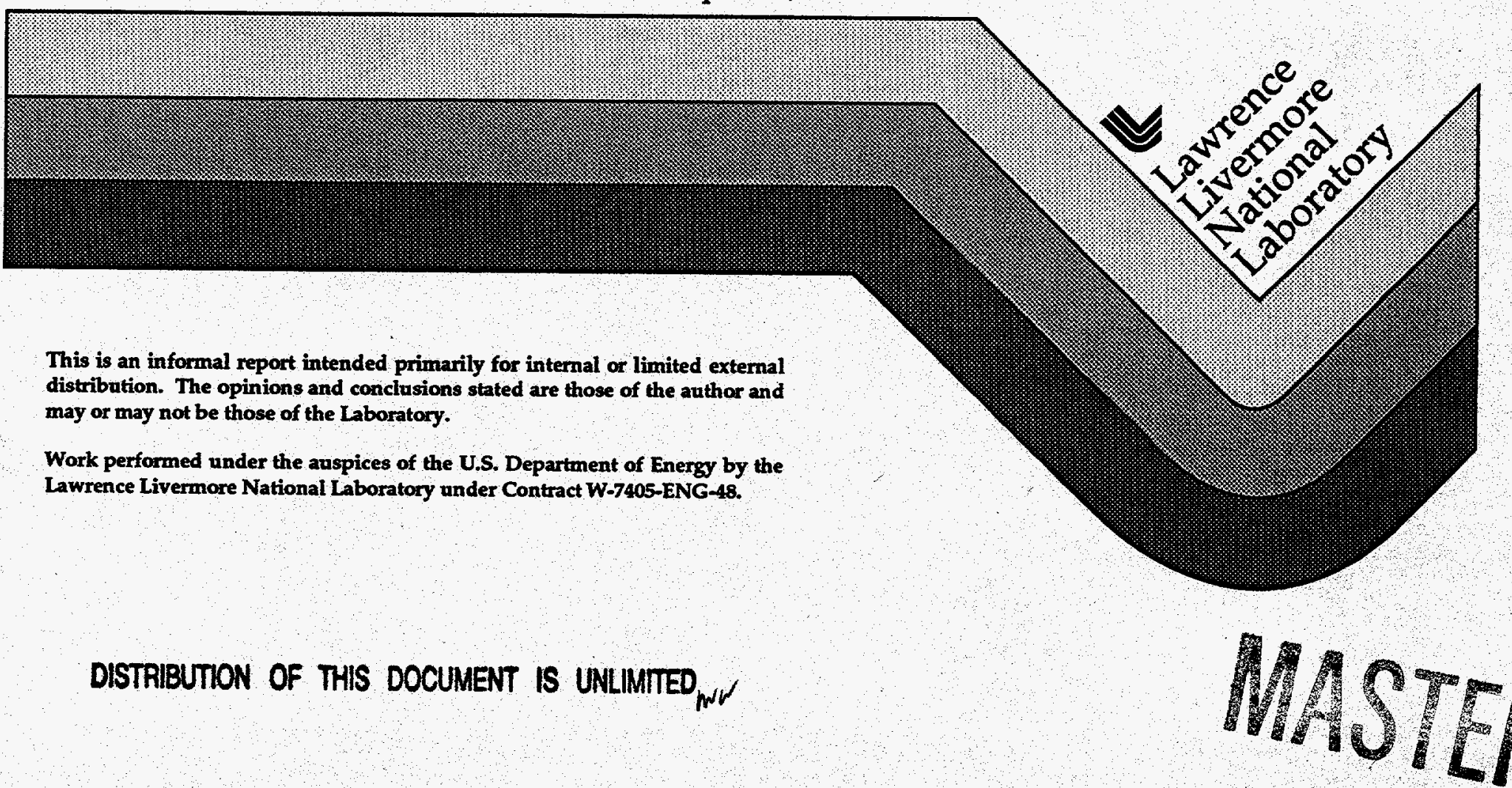




\section{DISCLAIMER}

This document was prepared as an account of work sponsored by an agency of the United States Government. Neither the United States Government nor the University of California nor any of their employees, makes any warranty, express or implied, or asoumes any legal liability or responsibility for the accuracy, completeness, or usefulness of any information, apparatus, product, or process disclosed, or represents that its use would not infringe privately owned rights. Reference herein to any specific commercial product, process, or service by trade name, trademark, manufacturer, or otherwise, does not necessarily constitute or imply its endorsement, recommendation, or favoring by the United States Government or the University of California. The views and opinions of authors expressed herein do not necessarily state or reflect those of the United States Government or the University of California, and shall not be used for advertising or product endorsement purposes.

This report has been reproctuced directly from the best available copy.

Available to DOE and DOE contractors from the

Office of Scientific and Technical Information

P.O. Box 62, Oak Ridge, IN 37831

Prices available from (615) 576-8401, FTS 626-8401

Available to the public from the

National Technical Information Service

U.S. Department of Commerce

5285 Port Royal Rd.,

Springfield, VA 22161 


\section{DISCLAIMER}

Portions of this document may be illegible in electronic image products. Images are produced from the best available original document. 
INTERDEPARTMENTAL LETTERHEAD

Mail Station $\quad L-490$

Ext $\quad 32075$

MEMORANDUM

LST-LDG95-010

CS\&T WBS 1.11, 2.7

April 20, 1995

To: Distribution

From: Janice Lawson

Subject: Simulation of phase structures

\section{The Question:}

Thanks to the super job that the members of the optics group (i.e., Bob Wolfe and team) have done measuring phase maps for optics in reflection and transmission, the modeling group has a stockpile of information about characteristic optics for the Beamlet and NIF laser systems. Among the measured parts are three Beamlet slabs, a crystal similar to a NIF switch crystal, crystals similar to NIF conversion crystals, and a diagnostic lens manufactured with a similar technique to that proposed for NIF spatial filter lenses. Each measurement gives us a look at the phase structure of that optic within the window and resolution of the measurement. But how do we then use that information in our modeling effort, especially the full aperture propagation calculations?

\section{The Beginning of an Answer:}

This memo outlines a procedure that I have developed to extract information from the phase measurements and produce a simulated phase structure for use in modeling. Inspiration for my approach came from a suggestion by Ken Manes to use the PSD in a method similar to the Nugent-type phase retrieval algorithm used for designing phaseplates. Our problem, however, is complicated by the desired change in grid size and resolution. To summarize the process briefly, I use a previously developed program (PHREAD) to read the phase measurements and calculate the power spectral density (PSD) of the phase map. I then extrapolate the PSD onto a grid of a chosen size and resolution. The PSD of the simulated surface is calculated by using the actual 
magnitude of the PSD and assigning random phases to the PSD. The phase map of the simulation is the Fourier transform of the constructed PSD.

Iterations between the $x-y$ and Fourier space assure that the solution is stable and has the properties (e.g., symmetry) required for a real phase structure. A listing of the actual program is attached. The language used is IDL, a graphicsoriented interactive data language written by Research Systems, Inc.

As input, we have large aperture measurements that show long spatial wavelength structures and small aperture measurements that show short spatial wavelength structure. For the simulations currently being used, a phase map was constructed using each measurement separately and then the phase maps were merged by simple addition. There is little frequency overlap between the large and small aperture measurements, however some does exist and, using this method, some double counting of frequencies does occur.

\section{The Details:}

If, for example, the desired grid for the simulation is $512 \times 512$ with each axis approximately $40 \mathrm{~cm}$ long then the smallest frequency interval on that grid is $1 / \mathrm{L}=0.0025 \mathrm{~mm}^{-1}$ and the maximum frequency observable is $256 / \mathrm{L}=0.64$ $\mathrm{mm}^{-1}$. If the measurement was over a $3.8 \mathrm{~cm} \times 3.8 \mathrm{~cm}$ area and had $258 \times 234$ resolution then the smallest frequency interval is $1 / \mathrm{L}=0.026 \mathrm{~mm}^{-1}$ and the maximum observable of about $128 / \mathrm{L}=3.4 \mathrm{~mm}^{-1}$. Thus, we only need a small, central portion of the original PSD to create our simulation. Fortunately, in the cases done to date, the portion of the PSD not used in the simulation contained little amplitude. In the program, the window of the original PSD to be used is specified as XW,YW in units of pixels. The size of the new grid is specified as $\mathrm{XD}, \mathrm{YD}$, again in units of pixels.

For the larger measurements, we face a slightly different problem. For example, if the measurement was over $27 \mathrm{~cm} \times 27 \mathrm{~cm}$ with a resolution of 154 $x 154$, then the smallest frequency interval would be $1 / \mathrm{L}=0.0037 \mathrm{~mm}^{-1}$ and the maximum observable would be about $77 / \mathrm{L}=0.29 \mathrm{~mm}^{-1}$. In this case, our window (XW and YW) covers the entire measured PSD and we only wish to change the frequency intervals to be consistent with our final simulation grid. The old information will fill a fraction, $F=(0.29 / 0.64)^{2}=0.45^{2}$ of our new simulation grid. So we need to create a grid about $230 \times 230$ with maximum frequency $0.45 \mathrm{~mm}^{-1}$ and place it on the empty simulation grid. In language that the program understands: $X W=Y W=154$ and $X D=Y D=230$.

As you can see from these numbers, all the information contained in the large aperture measurement lies in a $10 \times 10$ square region of the PSD corresponding to the small aperture experiment. In fact, most of the amplitude occurs over an even smaller $3 \times 3$ region. A quick look at this region of the small aperture measurement shows that a relatively small amount of 
amplitude occurs there (e.g., in the spatial frequency range $\mathrm{k}<0.05 \mathrm{~mm}^{-1}$, we measure 4.9 angstroms rms based on the small aperture measurement compared with 41 angstroms rms over a comparable frequency range on the large aperture measurement). Thus, adding the phase simulations based on the two types of measurement seems to be a reasonable approach to a confusing issue.

\section{How Does It Look?}

Figures 1,2, and 3 illustrate the process described above. Figure 1 is the phase map and PSD for a small aperture measurement of slab 19 (file cs1938at.phs). Figure 2 is the phase map and PSD for a large aperture measurement of the same slab (file cs19305t.phs). Figure 3 depicts a simulation that is the composite of information from these files. Notice that Fig. $3 b$ is similar in character to Fig. $1 \mathrm{c}$ and Fig. $3 \mathrm{c}$ is similar to Fig. 2c. The psd of the composite was not shown on a linear, full-grid scale as the data in Fig. 1 and 2 were, but looks nearly identical to Fig. $2 \mathrm{~b}$.

\section{What Next?}

To date, the simulations produced have been done for two slabs and are based on a single large aperture measurement and a single small aperture measurement for each slab. More variety can be achieved by using several of the small aperture measurements as a basis for the simulations. Although I haven't tried it, it may be possible to join a few sub-aperture simulations together to create a file where different regions show slightly different behavior. However, these refinements will be driven by the demand for more or different information. In the absence of that demand, the simulations produced to date will be assumed to be adequate and modification efforts will be low priority. High priority will be given to producing simulations of crystals, lenses and other optics (such as continuous melt glass or new polishing technique samples) so that we will have a more comprehensive analysis of the Beamlet and NIF laser systems.

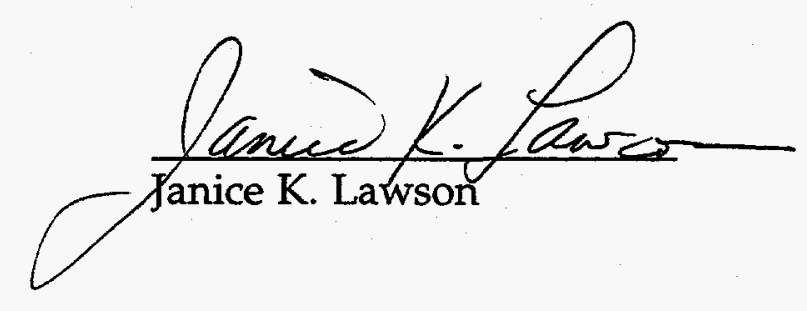




\section{GEN_PHS.PRO}

; Program to run after PHREAD++ to generate similar phase screens ; at larger scale size

;

; use psd to specify amplitudes at Fourier plane

;

$\mathrm{mfz}=\mathrm{abs}(\mathrm{sfsp})$

;

; Cut center region from grid and magnify

;

$\mathrm{mfz}=\mathrm{mfz}(\mathrm{x} 0-\mathrm{xw} / 2 . \mathrm{x} 0+\mathrm{xw} / 2 .-1, \mathrm{y} 0-\mathrm{yw} / 2 . \mathrm{y} 0+\mathrm{yw} / 2 .-1)$

$\mathrm{mfz}=$ congrid $(\mathrm{mfz}, \mathrm{xd}, \mathrm{yd}, /$ cubic $)$

;

; Generate random phases

;

$\mathrm{pfz}=\mathrm{randomu}(\text { seed }, \mathrm{xd}, \mathrm{yd})^{*} 2.0^{*} ! \mathrm{pi}$

;

; assemble far field

;

$\mathrm{fz}=\mathrm{mfz} z^{*} \exp (\operatorname{complex}(0, \mathrm{pfz}))$

$\mathrm{fz}=\operatorname{shift}(\mathrm{fz}, \mathrm{xd} / 2 ., \mathrm{yd} / 2$.)

;

; inverse transform, make real

;

$\mathrm{z} 2=$ float $(\mathrm{fft}(\mathrm{fz}, 1))$

;

; iterate to assure right symmetry, right mag psd

;

$\mathrm{fz}=\mathrm{fft}(\mathrm{z} 2,-1)$

$\mathrm{pf} z=\operatorname{atan}(\mathrm{imaginary}(\mathrm{fz})$, float $(\mathrm{fz}))$

$\mathrm{f} z=\operatorname{shift}(\mathrm{mfz}, \mathrm{xd} / 2 ., \mathrm{yd} / 2 .)^{*} \exp (\operatorname{complex}(0, \mathrm{pfz}))$

$\mathrm{z} 2=\mathrm{float}(\mathrm{fft}(\mathrm{fz}, 1))$

;

; Scale height to match previous rms

;

test=sqrt(total $\left.\left(\mathrm{z} 2^{*} \mathrm{z} 2\right) / \mathrm{xd} / \mathrm{yd}\right)$

$\mathrm{z} 2=\mathrm{z} 2^{*} \mathrm{rms} /$ test

;

; Generate axes in $\mathrm{cm}$

;

xpix2 $=0.1 /\left(x w^{*}\right.$ kxpix $)$

ypix $2=0.1 /\left(\mathrm{yw}^{*} \mathrm{kypix}\right)$

$x=(\text { findgen }(x d)-x d / 2 .-1)^{*} x p i x 2$

$\mathrm{y}=(\text { findgen }(\mathrm{yd})-\mathrm{yd} / 2 .-1)^{*} \mathrm{ypix} 2$

;

end 
Figure Captions:

Fig. 1 Analysis of small aperture $(3.8 \mathrm{~cm})$ measurement of slab 19: (a) phase map with spatial dimensions in $\mathrm{mm}$ and phase in angstroms, (b) PSD based on (a) - frequencies are given in $\mathrm{mm}^{-1}$ and PSD in angstroms ${ }^{2 *}$ microns $^{2}$, and (c) enhancement of the PSD plotted above displayed on a log scale with the frequency scale truncated to $\pm 1 \mathrm{~mm}^{-1}$.

Fig. 2 Analysis of large aperture $(30.5 \mathrm{~cm})$ measurement of slab 19: (a) phase map with spatial dimensions in $\mathrm{mm}$ and phase in angstroms, (b) PSD based on (a) - frequencies are given in $\mathrm{mm}^{-1}$ and PSD in angstroms ${ }^{2 *}$ micron $^{2}$, and (c) enhancement of the PSD plotted above displayed on a log scale with the frequency scale truncated to $\pm 0.1 \mathrm{~mm}^{-1}$.

Fig. 3 Simulation based on information from slab 19: (a) phase map with spatial dimensions in $\mathrm{mm}$ and phase in angstroms, (b) PSD based on (a) plotted with the PSD on a log scale - frequencies are given in $\mathrm{mm}^{-1}$ and PSD in angstroms ${ }^{2 *}$ microns ${ }^{2}$, and (c) enhancement of the PSD plotted above with the frequency scale truncated to $\pm 0.1 \mathrm{~mm}^{-1}$. 

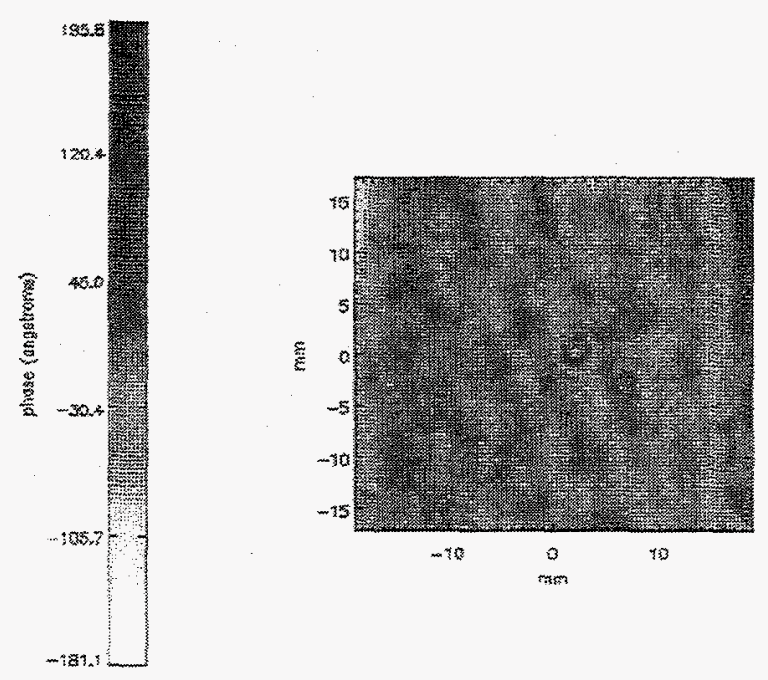

(a)
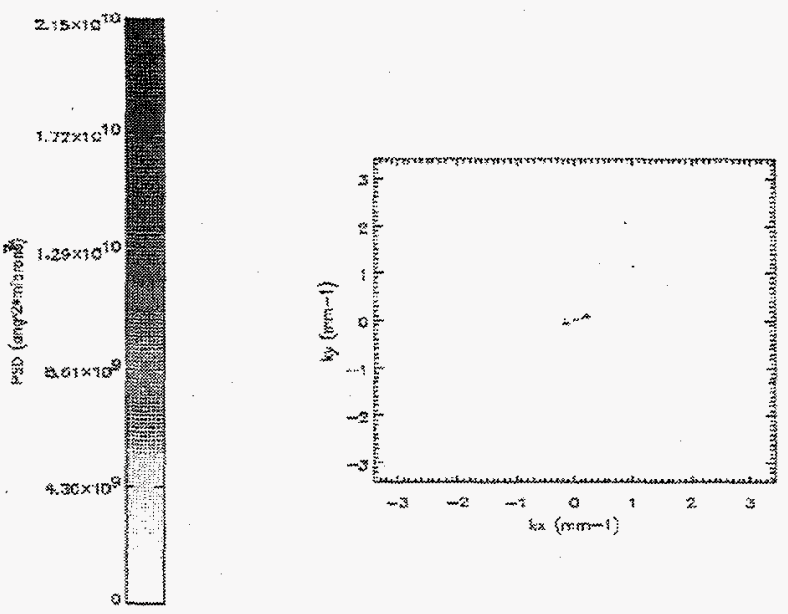

(b)
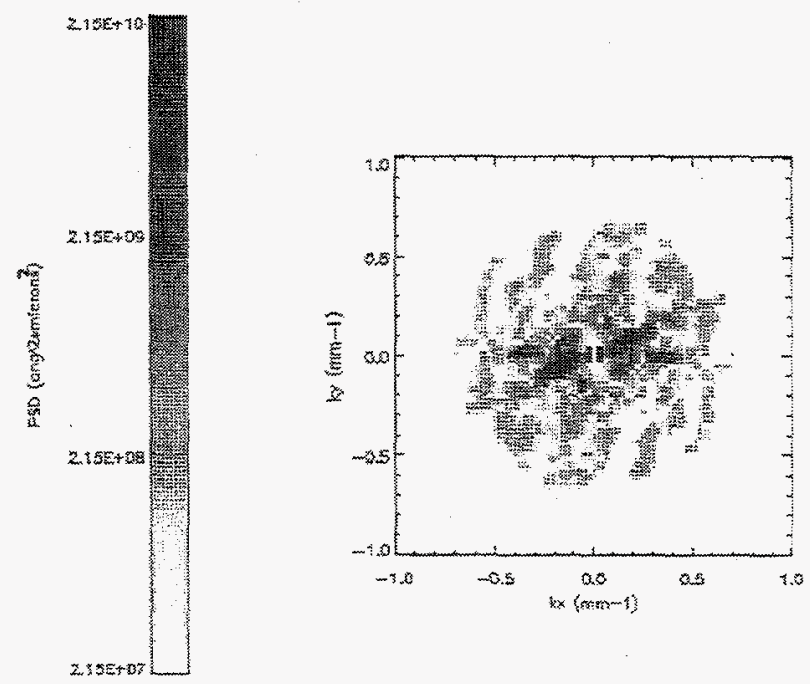

(c)

Figure 1 

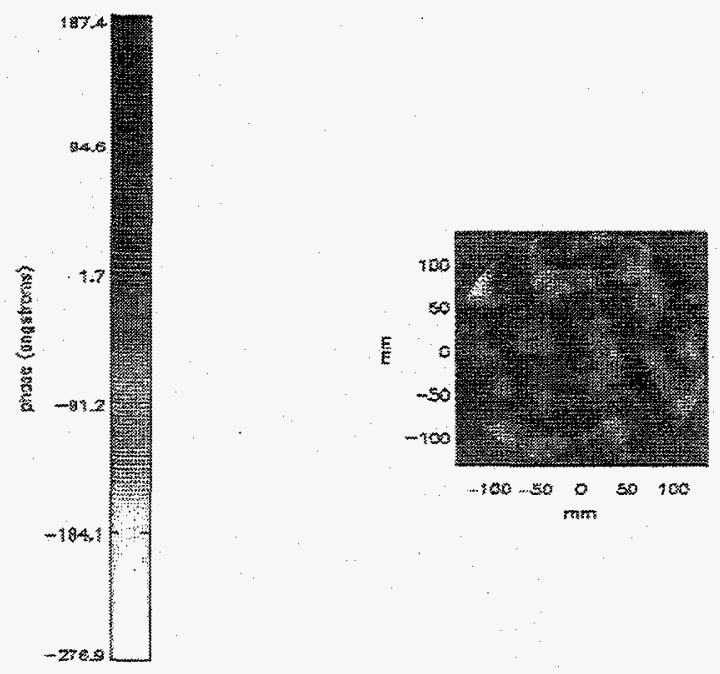

(a)
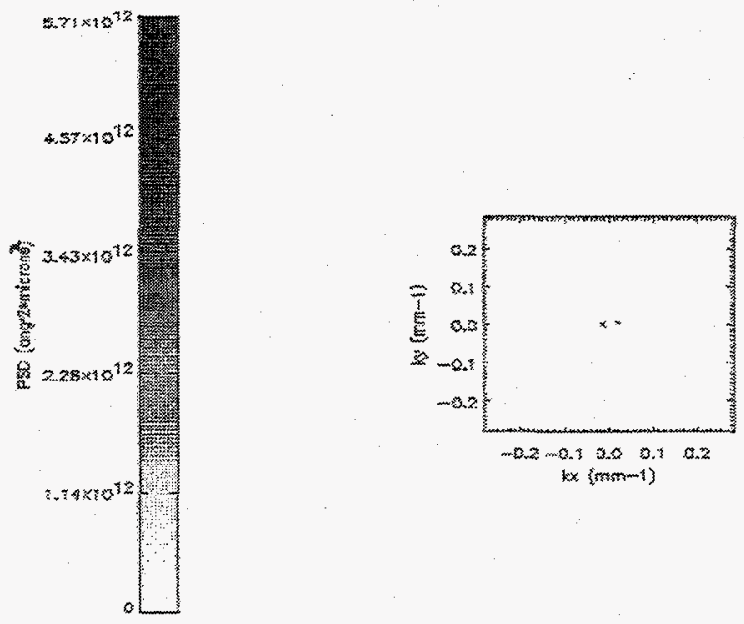

(b)
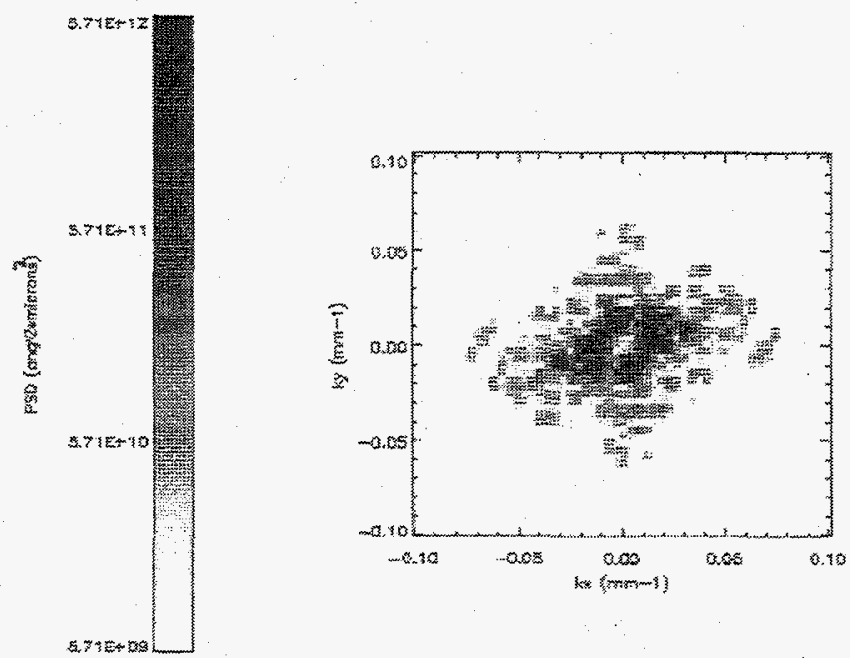

(c)

Figure 2 


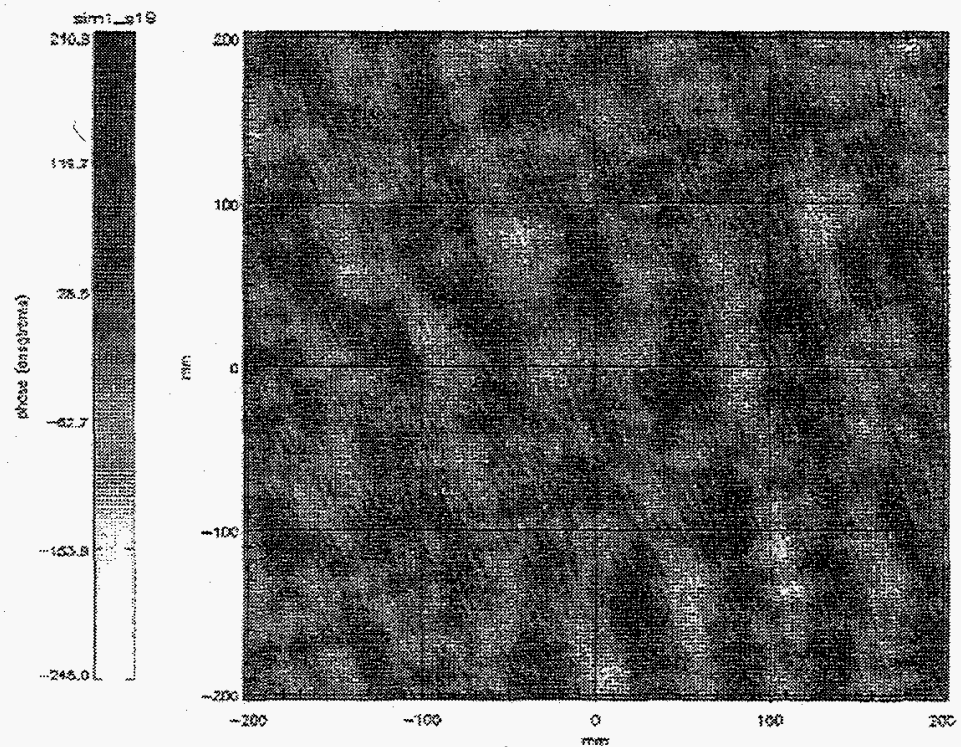

(a)
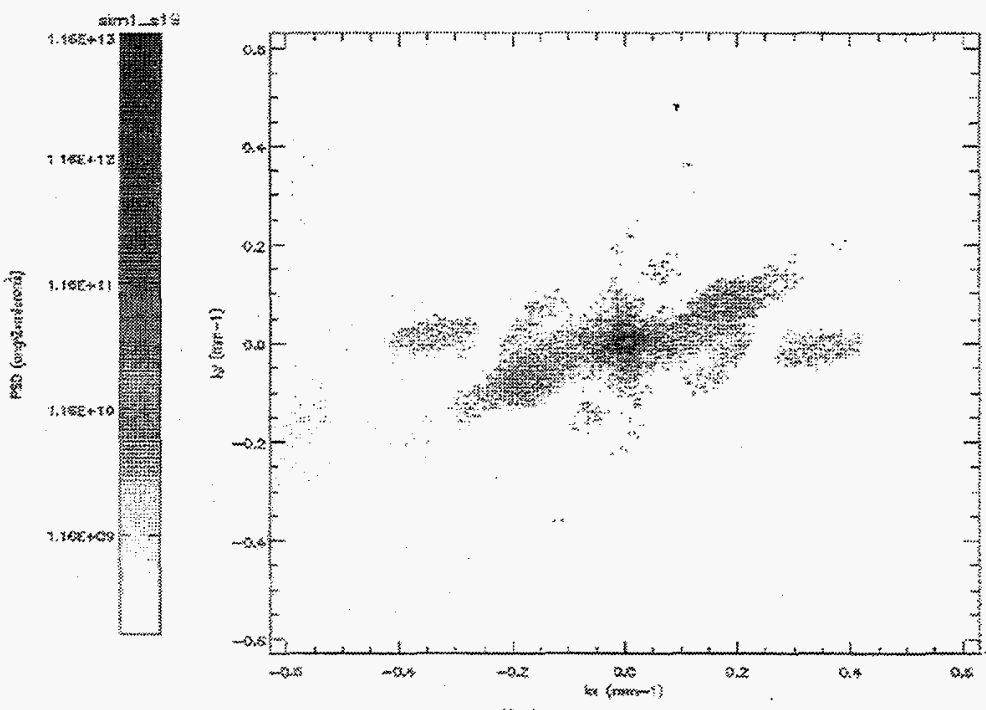

(b)
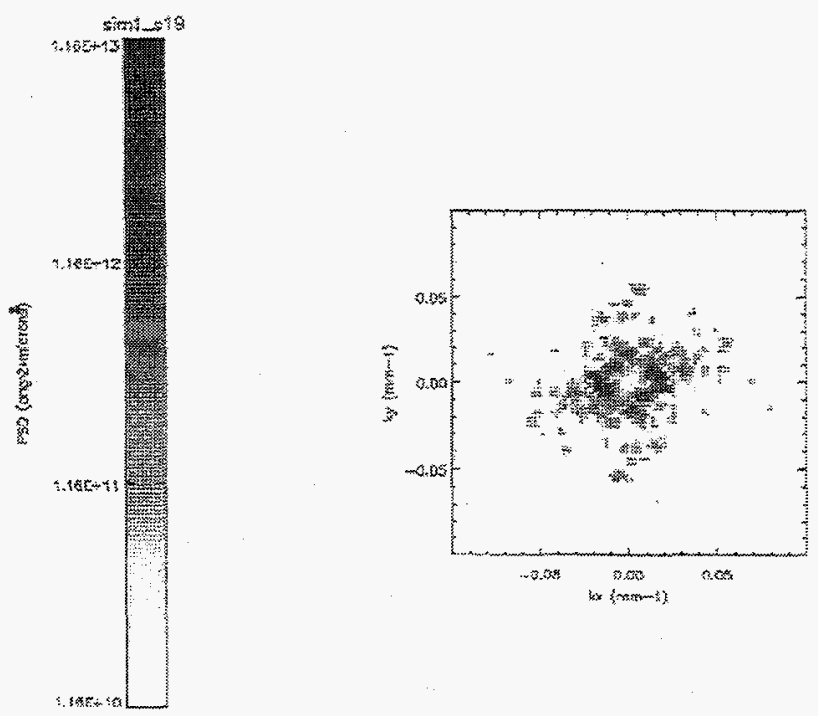

(c)

Figure 3 